\title{
Silica-waveguide thermooptic phase shifter with low power consumption and low lateral heat diffusion
}

\author{
Andersen, Bo Asp Møller; Jensen, Lars; Laurent-Lund, Christian; Thirstrup, Carsten
}

Published in:

I E E E Photonics Technology Letters

Link to article, DOI:

$10.1109 / 68.262559$

Publication date:

1993

Document Version

Publisher's PDF, also known as Version of record

Link back to DTU Orbit

Citation (APA):

Andersen, B. A. M., Jensen, L., Laurent-Lund, C., \& Thirstrup, C. (1993). Silica-waveguide thermooptic phase shifter with low power consumption and low lateral heat diffusion. I E E E Photonics Technology Letters, 5(12), 1415-1418. https://doi.org/10.1109/68.262559

\section{General rights}

Copyright and moral rights for the publications made accessible in the public portal are retained by the authors and/or other copyright owners and it is a condition of accessing publications that users recognise and abide by the legal requirements associated with these rights.

- Users may download and print one copy of any publication from the public portal for the purpose of private study or research.

- You may not further distribute the material or use it for any profit-making activity or commercial gain

- You may freely distribute the URL identifying the publication in the public portal 


\title{
Silica-Waveguide Thermooptic Phase Shifter with Low Power Consumption and Low Lateral Heat Diffusion
}

\author{
Bo Asp Møller, Lars Jensen, Member, IEEE, Christian Laurent-Lund, and \\ Carsten Thirstrup
}

\begin{abstract}
A thermooptic (TO) phase shifter consisting of a thin film heater on the top of a loaded stripline silica waveguide on a silicon substrate is shown to exhibit faster time response than reported for phase shifters based on a buried silica waveguide configuration. The rise time was measured to be $0.24 \mathrm{~ms}$, which is in good agreement with calculated thermal distributions in the structures. The lateral heat diffusion distance in the loaded stripline structure is shown to be smaller than in buried waveguide structures. This implies small thermal crosstalk and suggests a high-level integration of adjacent waveguides.
\end{abstract}

\section{INTRODUCTION}

$I^{\mathrm{N}}$ $\mathrm{N}$ general, glass has a temperature-dependent refractive index which is known as the thermooptic (TO) effect. Active optical glass waveguides utilizing the (TO) effect such as modulators and switches have been demonstrated [1]-[4]. In particular, a TO phase shifter is an important component for making silica-based integrated optical circuits on silicon substrates, where it is used in Mach-Zehnder optical multiplexers/demultiplexers and switches [5].

Conventional TO phase shifters consist of a thin film heater deposited on top of the cladding of a buried channel waveguide which provides a refractive index change [4]. Since the thermal conductivity is larger in glass than in air, the heat will be conducted to the silicon substrate which acts as a heatsink in this configuration. One of the problems with these TO phase shifters, however, is the relatively large power consumption and lateral heat diffusion in the glass, leading to a temperature rise of the sample and thermal crosstalk between two adjacent waveguides [4].

This paper describes a TO phase shifter implemented as a silica-based single-mode loaded stripline waveguide on a silicon substrate. In loaded stripline waveguides, a narrow thin film heater can be employed which ensures lower power consumption and less lateral heat diffusion than in buried waveguides. For the TO waveguide phase shifter reported here, the time response and the frequency response have been determined and the electrical power required for a $\pi$ phase shift of the light guided in

Manuscript received July 28, 1993; revised September 30, 1993.

The authors are with Microelectronik Centret, Technical University of Denmark, DK-2800, Lyngby, Denmark.

IEEE Log Number 9214042 . the waveguide has been measured by means of an external Mach-Zehnder interferometer. The lateral heat diffusion from the core region under the heater has been calculated and it is shown to be less than in a buried configuration.

\section{STRUCTURE AND EXPERIMENTS}

The TO phase shifter is fabricated as a single-mode silica-based loaded stripline waveguide with a chrome heater element on the top. The silica structure, supplied by Photonic Integration Research Inc., USA, consists of three layers deposited on a silicon wafer by Flame Hydrolysis Deposition. A cross section of the phase shifter is shown in Fig. 1. The load is $7 \mu \mathrm{m}$ thick and $14 \mu \mathrm{m}$ wide, the thicknesses of the core layer and the cladding layer are $6 \mu \mathrm{m}$ and $20 \mu \mathrm{m}$, respectively. The loads of the waveguides were made using reactive ion etching and a $0.44 \mu \mathrm{m}$ thin chrome film was used as an etch mask. Thus, the thin film heater was formed as a self-aligned structure on top of the waveguide load. The heaters were $5 \mathrm{~mm}$ long and $14 \mu \mathrm{m}$ wide, corresponding to the width of the waveguide load, and the electrical resistance of the heater was measured to be $1.56 \mathrm{k} \Omega$. The losses in the waveguides were measured to be $6.9 \mathrm{~dB} / \mathrm{cm}$ for TE polarization, and larger than $30 \mathrm{~dB} / \mathrm{cm}$ for $\mathrm{TM}$ polarization. For TE polarization, the high losses are due to a rough surface at the interface between the glass and the air caused by the etch process. By optimizing the etch process to eliminate the surface textures the losses can be reduced substantially [6]. For TM polarization, the additional losses are caused by the metal on top of the load.

In order to measure the thermally-induced phase shift, the TO waveguide phase shifter was placed in one arm of an external Mach-Zehnder interferometer. A GaInAsP laser with a wavelength of $1.55 \mu \mathrm{m}$ was used as the light source and the output light of the waveguides was detected by a GaInAs photodiode. Two types of experiments were carried out. In the first experiment, the frequency response of the TO phase shifter was determined by applying a triangular-wave voltage to the heater, and the phase shift was measured as a function of the applied electrical power. By tuning the frequency of the applied electrical power, the frequency characteristics were determined. The peak-to-peak voltage was set to $30 \mathrm{~V}$ and the 


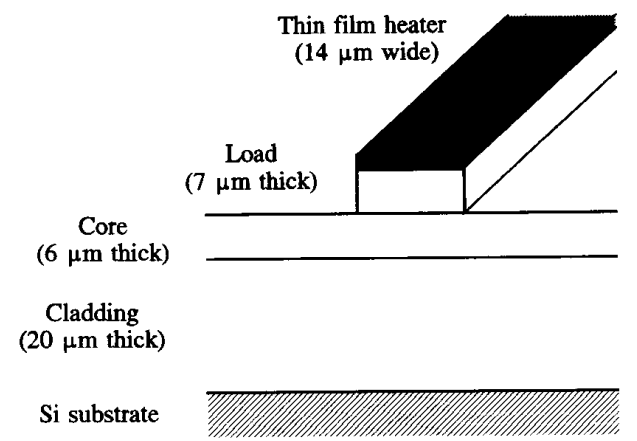

Fig. 1. Cross section of a TO phase shifter consisting of a single-mode loaded stripline silica waveguide on a silicon substrate with a chrome thin film heater on the top of the load.

frequency range was from $100 \mathrm{~Hz}$ to $2 \mathrm{kHz}$. In the second experiment, the time response of the TO phase shifter was determined by applying a voltage pulse to the heater. The pulse was a square pulse with a $7.5 \mathrm{~V}$ or $10 \mathrm{~V}$ amplitude, a frequency of $25 \mathrm{~Hz}$, and a duty cycle of $7.5 \%$, giving a pulse width of $3 \mathrm{~ms}$.

\section{Thermal ANALYSIS AND MEASUREMENTS}

A simple model can explain the dynamic behavior of the heat flow in the TO waveguide phase shifter. The heat from the chrome film diffuses into the silica glass, the air, and the silicon substrate. Because of the large thermal conductivity of silicon compared to silica and air, the substrate can be considered a perfect heat sink [4]. The air above and surrounding the phase shifter has a low thermal conductivity compared to chrome and glass, and the heat flow into the air can therefore be neglected. The thickness of the heater is much smaller than the thickness of the glass and the heat capacity of the film heater can therefore also be neglected. Using these assumptions, the temperature can be calculated using a finite difference method [7].

In the calculations, the applied electrical power was set equal to $0.5 \mathrm{~W}$, which is a typical value to obtain a $\pi$ phase shift of the light, and the temperature of the silicon substrate was kept constant at $300 \mathrm{~K}$. The power consumption required for a $\pi$ phase shift in the loaded stripline configuration was measured to be $0.4 \mathrm{~W}$, which is similar or better than reported in [4]. Material constants are the thermal conductivity of glass $\kappa=1.40 \mathrm{~W} / \mathrm{mK}$ [8], the specific heat of glass $c_{p}=840.0 \mathrm{~J} / \mathrm{kg} \cdot \mathrm{K}$ [9], and the mass density of glass $\boldsymbol{\rho}=2.21 \times 10^{3} \mathrm{~kg} / \mathrm{m}^{3}$ [8]. Four different configurations have been evaluated. Type $\mathrm{A}$ is a TO phase shifter based on a buried waveguide configuration with the vertical dimensions $21 \mu \mathrm{m}$ for the upper cladding, $8 \mu \mathrm{m}$ for the core, and $21 \mu \mathrm{m}$ for the lower cladding. The film heater width is $50 \mu \mathrm{m}$ [4]. Type B has the same dimensions as type A, except for the film heater width which is set equal to $14 \mu \mathrm{m}$. Type $\mathrm{C}$ is like type $\mathrm{B}$, but with thinner upper cladding and core. The vertical dimensions of this structure are $7 \mu \mathrm{m}$ for the upper
TABLE I

Calculated Rise Times for the Four TyPes (A-D) of Waveguide Structures, Shown Together WITH MEasured Rise Times

\begin{tabular}{lllll}
\hline \hline & \multicolumn{3}{c}{ Structures } \\
& Type A & Type B & Type C & Type D \\
\hline $\begin{array}{l}\text { Heater } \\
\text { width }(\mu \mathrm{m})\end{array}$ & 50 & 14 & 14 & 14 \\
$\begin{array}{l}\text { Upper clad } / \\
\text { load }(\mu \mathrm{m})\end{array}$ & 21 & 21 & 7 & 7 \\
$\begin{array}{l}\text { Core } \\
(\mu \mathrm{m})\end{array}$ & 8 & 8 & 6 & 6 \\
$\begin{array}{l}\text { Lower clad } \\
(\mu \mathrm{m})\end{array}$ & 21 & 21 & 20 & 20 \\
$\begin{array}{l}\text { Calculated } \\
\text { time } \\
\text { constant (ms) }\end{array}$ & 0.988 & 0.907 & 0.368 & 0.299 \\
$\begin{array}{l}\text { Measured } \\
\text { time } \\
\text { constant (ms) }\end{array}$ & 1.0 & & & \\
$\begin{array}{l}\text { Measured } \mathrm{P}_{\mathbf{1}} \\
\text { (W) }\end{array}$ & 0.44 & & & $0.24 \pm 0.01$ \\
\hline \hline
\end{tabular}

cladding, $6 \mu \mathrm{m}$ for the core, $20 \mu \mathrm{m}$ for the lower cladding, and the structure comprises a $14 \mu \mathrm{m}$ wide film heater. Type $\mathrm{D}$ is like type $\mathrm{C}$, but with a loaded stripline configuration, i.e., the upper cladding is etched except under the film heater (see Fig. 1).

For the four different configurations, the temperature at the center of the waveguide has been calculated as a function of time when a square pulse is applied to the heater. The resulting responses have the form of integrated error functions due to the diffusion nature of the problem. To a very good approximation, the integrated error function can be fitted by an exponential function and a time constant (rise time or fall time) can be defined. The rise times and fall times are measured to be equal within the uncertainty range, which is also expected from the linear model that describes the heat flow in the system. Table I shows the calculated rise times for the four different configurations (types A-D), and the measured rise times for the loaded stripline waveguide (type D from this work) and for the buried waveguide (type A from [4]). Fig. 2 shows the measured frequency response of the phase shifter, and the calculated frequency response for the four configurations as found from the calculated rise times. The normalized modulation with standard deviation for measured data is plotted as a function of frequency.

From Table I and Fig. 2, it is observed that the model agrees well with the measured data (type $A$ and type D). The large change in switching time between type $B$ and type $\mathrm{C}$ indicates that there are mainly two parameters which affect the switching speed and the power $P_{\pi}$ necessary to provide a $\pi$ phase shift. Most significantly, a smaller total volume of the glass will increase the switching speed because of the smaller heat capacitance. Secondly, a core closer to the heater will decrease the power needed for obtaining the same temperature in the core. 


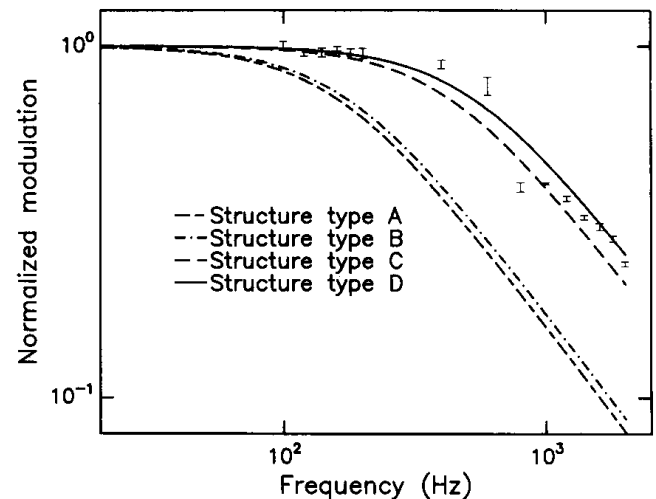

Fig. 2. Measured frequency response of the TO phase shifter (the error bars indicate the standard deviations of the measurements), and the calculated frequency response of (a) a buried waveguide structure with a total thickness of $50 \mu \mathrm{m}$ and a heater width of $50 \mu \mathrm{m}$ (type A), (b) As (a), but with a heater width of $14 \mu \mathrm{m}$ (type B), (c) a buried waveguide structure with a total thickness of $33 \mu \mathrm{m}$ and a heater width of $14 \mu \mathrm{m}$ (type C), and (d) a loaded stripline waveguide structure with a $7 \mu \mathrm{m}$ upper cladding, a $6 \mu \mathrm{m}$ core, a $20 \mu \mathrm{m}$ lower cladding and a heater with a width of $14 \mu \mathrm{m}$ (type D)

There is an additional increase of the switching speed from type $\mathrm{C}$ to type $\mathrm{D}$ since the load structure provides a stronger confinement of the heatflow than the buried waveguide structure. The difference between the switching times for type A and type B is small indicating that the phase shifter is not very sensitive to the width of the film heater. As a consequence of the effect of these parameters, the switching time for a loaded stripline waveguide structure is about four times smaller than for the buried waveguide structure reported by Sugita et al. [4] (see Table I). However, the increase in switching speed is obtained with penalty in optical losses. The smaller distance from the core to the heater leads to absorption of the TM polarized light [10].

Fig. 3 shows contour plots of the temperature in (a) a type A structure and (b) a type D structure. The thermal spreading, defined here as the lateral distance where the temperature rise is one-tenth of the temperature rise at the center of the waveguide core, is found to be $84 \mu \mathrm{m}$ for the type A structure and $39 \mu \mathrm{m}$ for the type D structure. This indicates the possibility of having waveguides more closely spaced and thereby minimizing the required space for, e.g., A Mach-Zehnder interferometer. Fig. 3 also shows the difference in core temperature for the two structures.

\section{CONCLUSIONS}

We have presented a thermooptic phase shifter fabricated as a single-mode loaded stripline silica waveguide on a silicon substrate with a thin film heater on the top of the load. A rise time of $0.24 \mathrm{~ms}$ was measured, which is faster than what has been achieved in TO phase shifters based on buried waveguides. The temperature distribution in the glass was calculated and the model showed good

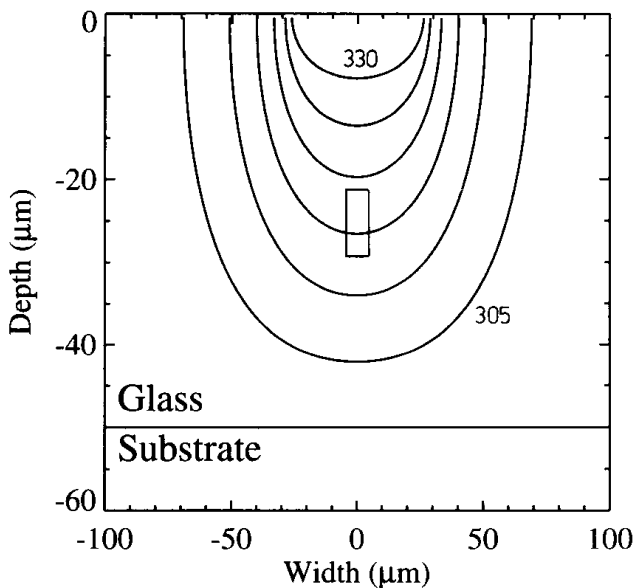

(a)

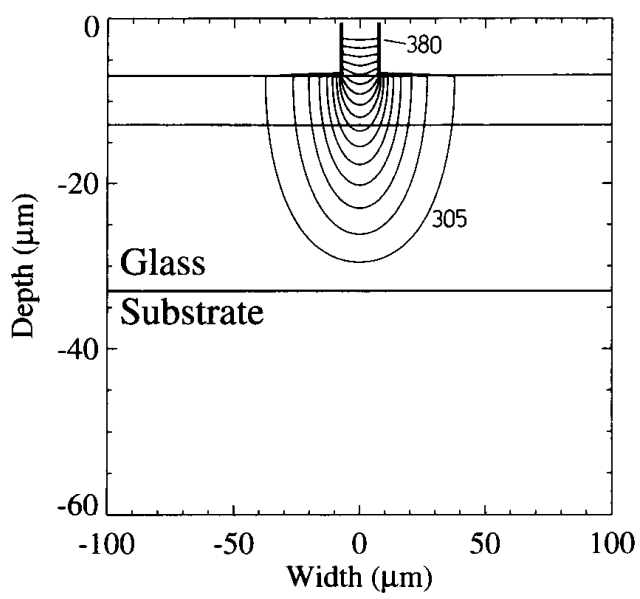

(b)

Fig. 3. Calculated temperature distribution in (a) a buried waveguide structure (type A), and (b) a loaded stripline waveguide structure (type D). The glass/substrate interface has a temperature of $300 \mathrm{~K}$, the applied electrical power is $0.5 \mathrm{~W}$, and the contour plots are shown in steps of $5 \mathrm{~K}$. The core regions of the waveguides are marked on the figures. Note that the $x$ axis and the $y$ axis have different scales.

agreement with the measured time response. The increased switching time is contributed to the smaller total glass volume and the shorter distance from the core to the heater. From the model, the lateral heat diffusion in the glass structure was calculated and it was found to be less than in a buried waveguide based TO phase shifter by a factor of two or more. The low lateral heat diffusion enables a higher integration-density of the waveguides.

\section{ACKNOWLEDGMENT}

The authors thank $O$. Hansen for his constructive comments and advice during our discussions, and G. Holm Larsen from Brüel \& Kjær A/S for providing help with the measurements. 


\section{REFERENCES}

[1] M. Haruna and J. Koyama, "Thermooptic deflection and switching in glass," Appl. Opt., vol. 21, pp. 3461-3465, 1982.

[2] N. Takato, K. Jinguji, M. Yaso, H. Toba, and M. Kawachi, "Silicabased single-mode waveguides on silicon and their application to guided-wave optical interferometers," J. Lightwave Technol., vol. 6, pp. 1003-1010, 1988.

[3] Y. Inoue, K. Katoh, and M. Kawachi, "Polarization sensitivity of a silica waveguide thermooptic phase shifter for planar lightwave circuits," IEEE Photon. Technol. Lett., vol. 4, pp. 36-38, 1992.

[4] A. Sugita, K. Jinguji, N. Takato, K. Katoh, and M. Kawachi, "Bridge-suspended silica-waveguide thermooptic phase shifter and its application to Mach-Zehnder type optical switch," Trans. IEICE, vol. E73, no. 1, pp. 105-109, Jan. 1990.
[5] M. Kawachi, "Silica waveguides on silicon and their application to integrated-optic components," Opt. Quantum Electron., vol. 22, pp. 391-416, 1990.

[6] L. Jensen and B. Asp Møller, "Glass waveguides on a silicon substrate," Master of Science Thesis, Mikroelektronik Centret, Tech. Univ. Denmark, Jan. 1993 (in Danish).

[7] W. E. Milne, Numerical Solution of Differential Equations. New York: Dover, 1970.

[8] A. S. Grove, Physics and Technology of Semiconductor Devices. New York: Wiley, 1967.

[9] Kaye \& Laby, Tables of Physical and Chemical Constants. New York: Longman, 1986.

[10] H. Nishihara, M. Haruna, and T. Suhara, Optical Integrated Circuits. New York: McGraw-Hill, 1989.

\title{
ARROW-Type Polarizer Utilizing Form Birefringence in Multilayer First Cladding
}

\author{
Y. Kokubun and S. Asakawa
}

\begin{abstract}
We proposed a novel waveguide polarizer using an ARROW structure, of which the first cladding consists of three thin layers. Theoretical calculation shows that this polarizer can achieve a high isolation over $30 \mathrm{~dB} / \mathrm{cm}$ with small insertion loss of $0.01 \mathrm{~dB} / \mathrm{cm}$ at the wavelength of $1.3 \mu \mathrm{m}$. The isolation of $83 \mathrm{~dB} / \mathrm{cm}$ with the insertion loss of $4.3 \mathrm{~dB} / \mathrm{cm}$ was experimentally obtained at the wavelength of $0.633 \mu \mathrm{m}$. This structure is suitable for the integration of a polarization splitter and photodetector.
\end{abstract}

\section{INTRODUCTION}

$\mathbf{P}$ HOTONIC circuits based on multilayer waveguides are suitable for various functional devices, and for a dense integration of photonic circuits with stacked configuration. In particular, ARROW (antiresonant reflecting optical waveguide) [1], [2] has many advantages for such integrated photonics on a semiconductor substrate. We have reported some applications of ARROW's, such as a wavelength filter [3], an integrated structure of a waveguide and photodetector [4], and a stacked configuration of ARROW's [5], [6]. One of the advantage of an ARROW is the strong polarization dependence of propagation loss, i.e., only the $\mathrm{TE}_{0}$ mode can be guided with low loss, while the $\mathbf{T M}_{0}$ mode is radiated to the substrate. However, when the core thickness is as thick as that of optical fibers, the $\mathrm{TM}_{0}$ mode loss is not large enough for a compact waveguide polarizer. This is because the ratio

Manuscript received June 29, 1993; revised August 31, 1993.

The authors are with Yokohama National University, Division of Electrical and Computer Engineering, Hodogayaku, Yokohama, 240 Japan.

IEEE Log Number 9214110 of radiation losses of the $\mathrm{TE}_{0}$ and $\mathrm{TM}_{0}$ modes in $\mathrm{dB}$ is almost constant for any combination of materials, i.e., the core and first cladding materials. On the other hand, when the core thickness decreases, the isolation is high enough for a compact device. However, a spot-size transformer is needed in the circuit.

On the other hand, several waveguide polarizers have been developed by using a selective attenuation in a metal cladding [7] or a semiconductor cladding 8], and a selective cutoff in a birefringent cladding consisting of a single crystal [9]. However, these polarizers have some drawbacks such as the insufficient low-insertion loss of transmitted light and the difficulty in fabrication.

In this letter, we introduce a novel ARROW-type polarizer of which the first cladding consists of alternate high-index and low-index layers to produce so-called Form birefringence. This polarizer can achieve a high-isolation and low-insertion loss for any core thickness. The design and fabrication of the ARROW-type polarizer will be presented.

\section{StRucture AND DESIGN}

In the fundamental structure of ARROW, an interference cladding which is sandwiched between the core and the substrate consists of a high-index layer designated the first cladding and a low-index layer designated the second cladding as shown on the left of Fig. 1. The radiation loss characteristics of $\mathrm{TE}_{0}$ and $\mathrm{TM}_{0}$ modes plotted against the thickness of the first cladding (single layer) are shown by dash-dotted and dash-double-dotted lines, respectively, in Fig. 2. The radiation losses of $\mathrm{TE}_{0}$ and $\mathrm{TM}_{0}$ modes

$1041-1135 / 93 \$ 03.00$ 다 1993 IEEE 